\begin{tabular}{|l|l|}
\hline $\begin{array}{c}\text { European Association for the } \\
\text { Development of Renewable Energies, Environment } \\
\text { and Power Quality (EA4EPQ) }\end{array}$ & $\begin{array}{l}\text { International Conference on Renewable Energies and Power Quality } \\
\text { (ICREPQ'12) } \\
\text { Santiago de Compostela (Spain), 28th to 30th March, 2012 }\end{array}$ \\
\hline
\end{tabular}

\title{
Low-Cost Instrument for Tracing Current-Voltage Characteristics of Photovoltaic Modules
}

\author{
Vicente Leite ${ }^{1}$ José Batista $^{2}$, Faustino Chenlo ${ }^{3}$ and João L. Afonso ${ }^{4}$ \\ ${ }^{1,2}$ Polytechnic Institute of Bragança, School of Technology and Management \\ Campus Santa Apolónia, apartado 1134, Bragança, Portugal \\ ${ }^{1}$ avtl@ipb.pt, ${ }^{2}$ jbatista@ipb.pt \\ ${ }^{3}$ CIEMAT, Research Centre for Energy, Environment and Technology \\ Av. Complutense 22, Madrid, España \\ faustino.chenlo@ciemat.es \\ ${ }^{4}$ Centro Algoritmi, Univ. Minho, Department of Industrial Electronics \\ Campus de Azurém, 4800-058 Guimarães, Portugal \\ jla@dei.uminho.pt
}

\begin{abstract}
This paper presents a simple, robust and low-cost instrument for tracing current- and power-voltage characteristics of photovoltaic modules or low voltage strings using either an oscilloscope or a LabVIEW application developed for this purpose. It consists of a flexible electronic circuit, developed from a previous work, based on a fast varying load, built with a power MOSFET, which is controlled by means of a suitable gate-source voltage control signal in order to improve the tracing of current- and powervoltage characteristics on an oscilloscope. The new developments of this work include a low-cost DAQ system and an application developed in LabVIEW, which enhances the functionalities and flexibility of the current-voltage tracer. The robustness was strongly improved in view of field tests for fault diagnosis analysis. All details of the electronic circuit are shown in this paper and experimental results obtained with the new instrument are presented.
\end{abstract}

\section{Key words}

Photovoltaic Modules, I-V and P-V Characteristics, I-V Tracer, LabVIEW, Fault Diagnosis.

\section{Introduction}

Photovoltaic (PV) energy is booming and a widespread use of low power of distributed PV systems is now a reality because of the modularity of PV technology, which is used even for sizing high power PV plants. The growth of the annual market regarding PV industry is evident in many countries [1], [2]. Installations of PV modules around the world have been growing at a very high average annual rate, and it was $46.2 \%$ between 2000 and 2009 in the countries reported in [1]. By the end of 2009, the cumulative installed capacity of all PV systems around the world had surpassed $23 \mathrm{GW}$ [2]. According to this report, by 2030 the capacity of installed PV systems could be around 1,082 GW under an accelerated scenario, and 1,845 GW under the so called "paradigm shift scenario". Furthermore, by 2050 there could be over $4,500 \mathrm{GW}$ of PV installed world-wide under this latest scenario [2]. Thus, it becomes evident that one can expect a very strong transformation and expansion of the PV industry sector over the coming decades.

In spite of their well known reliability, some PV modules degrade or even fail when operating outdoors for extended periods, and that can occur in a number of ways [3]. In the degradation diagnosis in PV cells of modules and strings, the Current-Voltage (I-V) characteristics are usually used, as well as parameters obtained from them, like short-circuit current $\left(I_{S C}\right)$, open-circuit voltage $\left(V_{O C}\right)$, maximum power $\left(P_{\max }\right)$ and fill factor $\left(\mathrm{FF}=P_{\max } / I_{S C} V_{O C}\right)$. On the other hand, the $\mathrm{I}-\mathrm{V}$ characteristics can be monitored and the results used to investigate and to compare the actual power produced by modules under realistic operating conditions [4]. Thus, I-V characteristics are not only used by designers in power converter systems, but also in PV systems design, to make these systems more cost effective.

Photovoltaic modules are usually tested using electronic DC loads, which can vary the load resistance over the entire range in a very short time. However, the ones available on the market are often expensive. Anyway, by using quite simple and much cheaper circuits, it is also possible to build an electronic DC load taking advantage of a suitable operation of a power MOSFET, as described in [5]. In fact, a power MOSFET operating in the active region can be used as an electronic load to test PV modules [4] - [7].

Some simple and/or low cost electronic circuits have been developed along this decade. In [8] simple and low cost electronic circuits that facilitate the data acquisition of $\mathrm{I}-\mathrm{V}$ characteristics of PV cells were proposed. The I-V characteristics of PV modules were measured in [9], with a swept method by charging a capacitor. This principle was 
used recently in [10] for in-door I-V curve trace of PV modules. In [4] it is reported the design of a low-cost measuring system used to monitor the I-V characteristics of PV modules. The system was previously developed in [11] and measures I-V characteristics of seven different modules sequentially by selecting a module through mechanical relays. Other set of relays are used to select a parallel combination of resistors used as resistive loads for a particular I-V pair of values. By using a combination of resistors, several resistances are achieved to measured I-V pairs. A more interesting electronic circuit, being a fast varying load, is presented in [7]. The circuit is based on a MOSFET operating in its linear region and the proposed circuit traces the I-V and P-V characteristics of PV modules by quickly scanning the load by sweeping the $V_{G S}$ (gate to source voltage) of the MOSFET with a sinusoidal waveform. Other parameters are also provided. The power generated by the PV module is dissipated in a series power resistor.

In [5] an improved electronic circuit was presented to test PV modules by tracing their I-V and P-V characteristics. As in [7] it was based on a power MOSFET but the scanning voltage $\left(V_{G S}\right)$ was achieved in an innovative way in order to improve the I-V tracing on an oscilloscope. Moreover, galvanic isolation was introduced to prevent damage of data acquisition systems and to enable the circuit to be used in tests of PV strings.

In this paper all details of the electronic circuit of the previous work [5] are shown and the new developments are presented aimed to improve the robustness of tracing I-V characteristics in view of field tests for fault diagnosis analysis. The new developments include a low-cost DAQ system and a LabVIEW application, which was developed with virtual instruments to enhance the new PV instrument, or I-V tracer, with additional functionalities and flexibility.

\section{Description of the Electronic Instrument}

A general scheme of the proposed electronic circuit to test PV modules is shown in Fig. 1 and a simplified scheme of the new instrument is shown in Fig. 2. It is based on the previous electronic circuit described in [5], where part of the original electronic circuit was replaced by a LabVIEW application.

In these figures, $V_{G S}$ is the gate-source voltage, $V_{P V}$ and $I_{P V}$ are the output voltage and current of the PV module, $I_{S C}$ is the short-circuit current and $V_{O C}$ is the open circuit voltage, $V_{M P P}$ and $I_{M P P}$ are the voltage and current at the Maximum Power Point (MPP), $\mathrm{R}_{\mathrm{Vpv}}$ and $\mathrm{R}_{\mathrm{Ipv}}$ are measurement resistors for $V_{P V}$ and $I_{P V}$, and $\mathrm{R}_{\mathrm{p}}$ is the selectable power resistor for different measurement scales of $V_{P V}$.

The tracing of the I-V and P-V characteristics is achieved by using the MOSFET IRFP260N as an electronic fast continuous varying load, which principle of operation has been described in [5]. A high voltage MOSFET or an IGBT can be used to trace the I-V and P-V characteristic of strings, but it should be noticed that the power of the string is limited by the safe operating area of the power device, since it cannot stand a high power for more than some milliseconds as

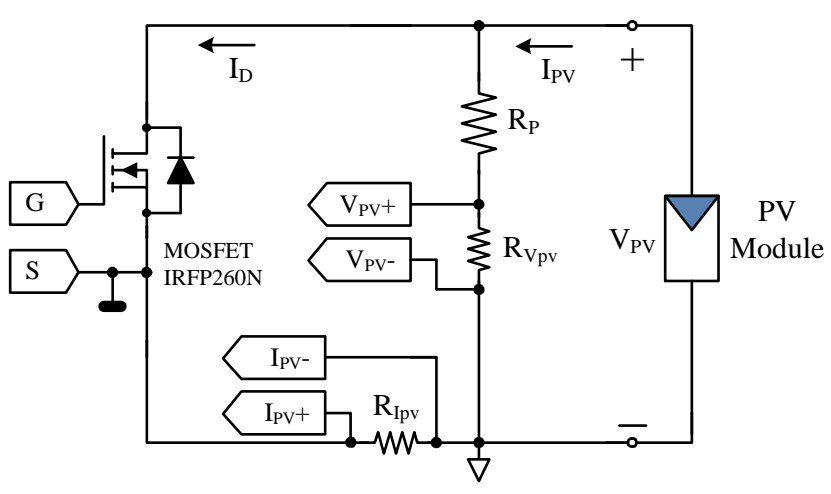

Fig. 1. Electronic circuit for tracing $\mathrm{I}-\mathrm{V}$ and $\mathrm{P}-\mathrm{V}$ characteristics of photovoltaic modules.

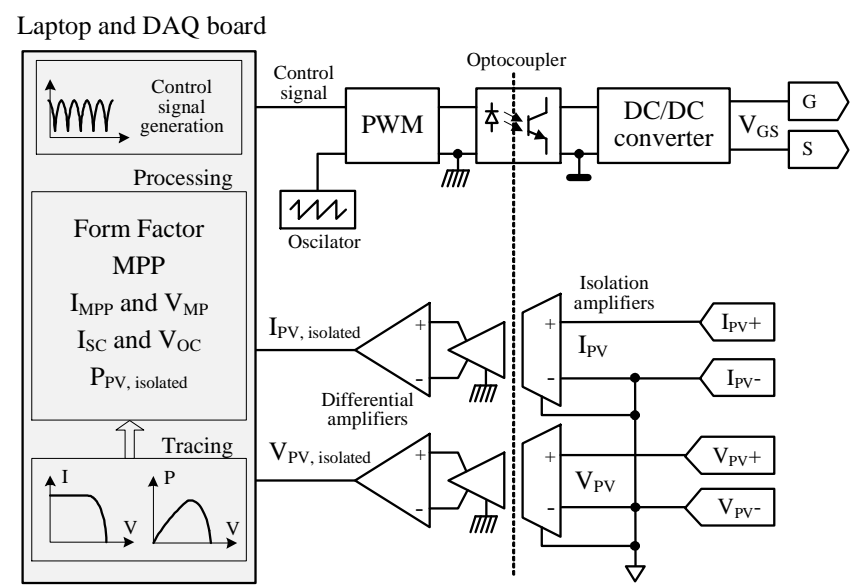

Fig. 2. Simplified scheme of the new proposed instrument.

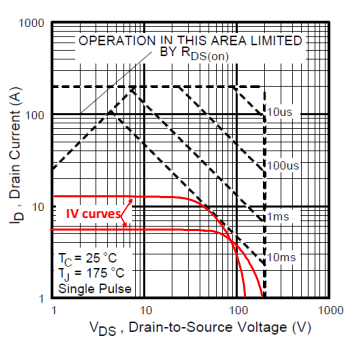

(a)

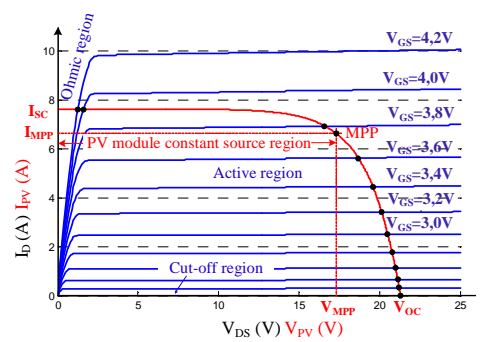

(b)
Fig. 3. Characteristics of the MOSFET and PV module: (a) IRFP260N Safe Operating Area; (b) Characteristic of a PV module at STC (red curve) and characteristics of a MOSFET (blue curves).

shown in Fig. 3(a), for the MOSFET IRFP260N, where some hypothetical I-V curves are superimposed to illustrate that these curves must be inside the limits of the safe operating area. The $I_{D^{-}} V_{D S}$ characteristics of a MOSFET, shown in Fig. 3(b), are given by the equations (1a) and (1b) for ohmic region, where $V_{D S}<V_{G S^{-}} V_{t h}$, and active region, where $V_{D S}>V_{G S^{-}}$ $V_{t h}$, respectively [12].

$$
\begin{gathered}
I_{D}=K\left(2\left(V_{G S}-V_{t h}\right) V_{D S}-V_{D S}^{2}\right) \approx 2 K\left(V_{G S}-V_{t h}\right) \\
I_{D}=K\left(V_{G S}-V_{t h}\right)^{2}\left(1+\lambda V_{D S}\right)
\end{gathered}
$$


Each characteristic corresponds to a given gate-source voltage $\left(V_{G S}\right) . K$ and $\lambda$ are device parameters and $V_{t h}$ is the threshold (gate) voltage. On the other hand, the $I_{P V^{-}} V_{P V}$ characteristic of a PV module is given by equation (2) where $I_{L}$ is the light-generated current $\left(=I_{S C}\right), I_{O}$ is the darksaturation current, $n$ is the diode ideality factor (a number between 1 and 2) and $V_{T}$ the thermal voltage [13].

$$
I_{P V}=I_{L}-I_{\text {diode }}=I_{L}-I_{O}\left(e^{V_{P V} / n V_{T}}-1\right)
$$

$I_{L}$ is the light-generated current $\left(=I_{S C}\right), I_{O}$ is the darksaturation current, $\mathrm{n}$ is the diode ideality factor (a number between 1 and 2) and $V_{T}$ the thermal voltage [13].

As far as the PV module is concerned, for $V_{P V}$ higher than the voltage at the maximum power point $\left(V_{M P P}\right)$ the characteristic will be similar to a voltage source one. In this flat region, shown in Fig. 3(b), the voltage $V_{P V}$ is sensitive to small variations in current $\left(I_{P V}\right)$ and hence to small variations in $V_{G S}$. Because of this high sensitivity, the operating point will move too fast in this flat region. In [5] an improved sweeping signal was proposed to generate a suitable $V_{G S}$ voltage consisting of an isolated, low frequency rectified sinusoidal with adjustable maximum and minimum levels. This signal is used to control the MOSFET shown in Fig. 1 and the result is a continuous tracing of the $\mathrm{I}-\mathrm{V}$ and $\mathrm{P}-\mathrm{V}$ characteristics of a PV module.

The individual electronic circuits of Fig. 2 are shown in Fig. 4. The first circuit, shown in Fig. 4(a), is used to control the MOSFET of Fig. 1. First, it provides galvanic isolation by means of an optocoupler and second, it reproduces the control signal converting a PWM signal into the corresponding analogue voltage as illustrated in Fig. 4(a). The circuit of Fig. 4(b) is used for isolated measurement of current and voltage of the PV module. It uses two HCPL7800 isolation amplifiers followed by simple differential amplifiers. The isolated output voltage and current signals are sampled by a DAQ board to trace the I-V and P-V characteristics using a laptop and virtual instruments developed in a LabVIEW application.

As can be seen from Fig. 1 the MOSFET drain current and the PV module current $\left(I_{P V}\right)$ are the same, since the current in the voltage divider, formed by $R_{P}$ and $R_{p v}$, is negligible. Therefore, the operating point is given by the intersection of the PV module characteristic with the MOSFET one for a given voltage $V_{G S}$, as shown in Fig. 3(b). While $V_{G S}$ is less than the threshold voltage $V_{t h}$, the MOSFET will be OFF. When $V_{G S}$ is increased above $V_{t h}$, the device will operate in its active region where the drain current rises linearly with $V_{G S}$. Thus, by sweeping $V_{G S}$ with a suitable signal the operating point of the MOSFET sweeps the $I_{P V}-V_{P V}$ characteristic between $V_{O C}$ and $I_{S C}$ [5]. For PV modules and when only is available an oscilloscope, this $V_{G S}$ voltage is generated through the circuit shown in Fig. 5(a) which is a precision rectifier with a suitable gain and a variable positive DC offset voltage. The input is a low frequency sinusoid generated by the oscillator shown in Fig. 5(b) based on the MAX038. However, when a DAQ system is available, the LabVIEW application developed in this work replaces these two circuits of Fig. 5(a) and 5(b).

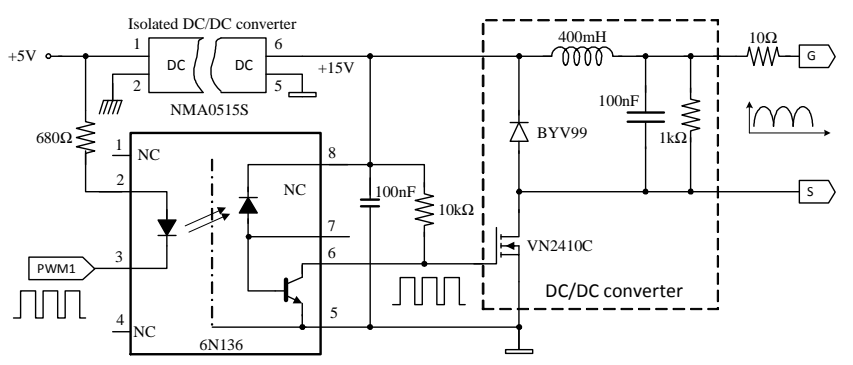

(a)

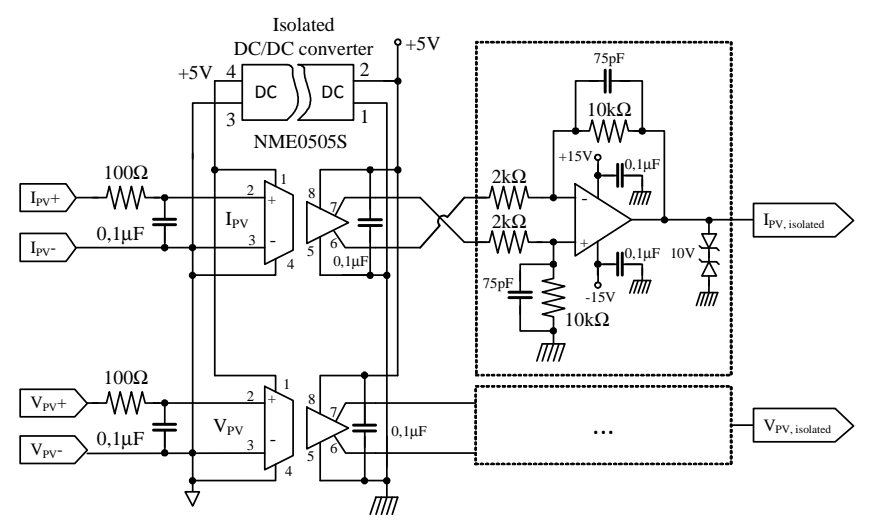

(b)

Fig. 4. Individual electronic circuits providing galvanic isolation: (a) DC/DC converter for the conversion of the digital pulses into the corresponding MOSFET voltage control; (b) Current and voltage measurement circuit.

The output voltage of Fig. 5(a) is the reference of the control voltage $V_{G S}$ that controls the MOSFET of Fig. 1. This voltage is converted into pulses with a duty cycle proportional to its amplitude. This is done by using a PWM circuit built with the comparator $\mathrm{C}$ of Fig. 5(d) and the sawtooth generator shown in Fig. 5(c) which is based on the NE555 and generates a sawtooth carrier with a frequency of $11 \mathrm{kHz}$. The galvanic isolation of the digital pulses is made by the optocoupler 6N136. Galvanic isolation is particularly important when the voltage across the PV module and the output current are to be measured with a digital acquisition system or when a PV string is to be tested instead of a module.

The digital pulses are converted again into an analogue voltage by means the DC/DC converter shown in Fig. 4(a). This voltage corresponds to the voltage $V_{G S}$ that will control the MOSFET of Fig. 1 producing a proportional drain current which is the same of the PV module.

By using a DAQ board, the I-V and P-V characteristics are plotted on a XY graph using the LabVIEW application developed in this work, which is described in the next section. Nevertheless if only a digital oscilloscope is available, the isolated output current and voltage of Fig. 4(b) are multiplied by the analogue multiplier MPY634, as shown in Fig. 5(e), in order to also trace the P-V characteristic.

In conclusion, it is clear that all electronic circuits are based on simple, widely used and low-cost components. 


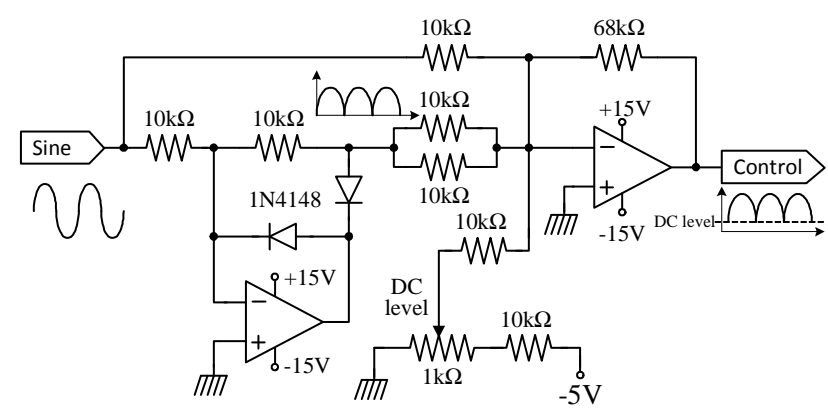

(a)

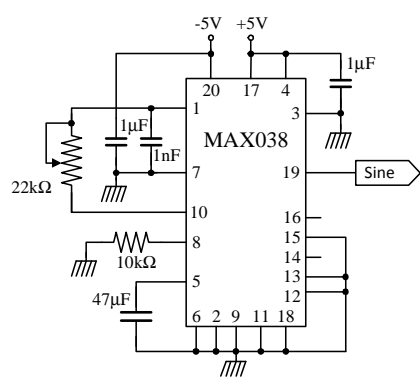

(b)

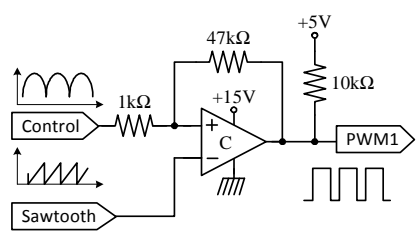

(d)

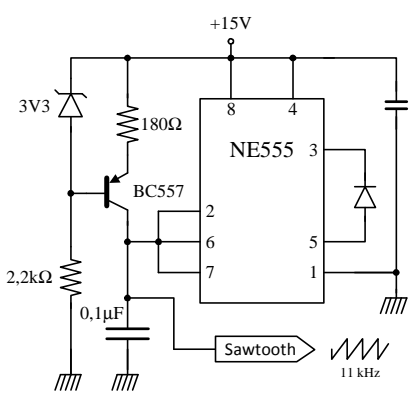

(c)

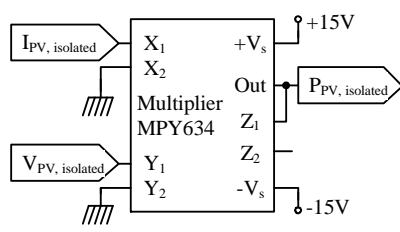

(e)
Fig. 5. Auxiliary electronic circuits: (a) Sweeping voltage $V_{G S}$ for continuous tracing of PV modules; (b) Sinusoidal generator; (c) Sawtooth generator; (d) PWM circuit; (e) Multiplier.

\section{The Developed LabVIEW Application}

This section presents a powerful and flexible alternative to the setup based on an oscilloscope. This alternative is based on a low-cost DAQ system which enhances the functionalities of the I-V tracer. This DAQ system is based on the NI-USB 6008 data acquisition board, a laptop and a application developed in LabVIEW with an interface based on virtual instruments. Besides the same functionalities obtained by means of an oscilloscope, either in YT or in XY mode, the new setup can easily provide very important parameters such as $V_{O C}, I_{S C}, V_{M P P}, I_{M P P}$ and form factor. Furthermore, all the acquired data can be saved for future digital processing and analysis.

The LabVIEW application and its interface is shown in Fig. 6 and allows tracing the I-V and $\mathrm{P}-\mathrm{V}$ characteristics of modules. In this case the PWM control signal is generated by the LabVIEW application instead of the analogue circuit

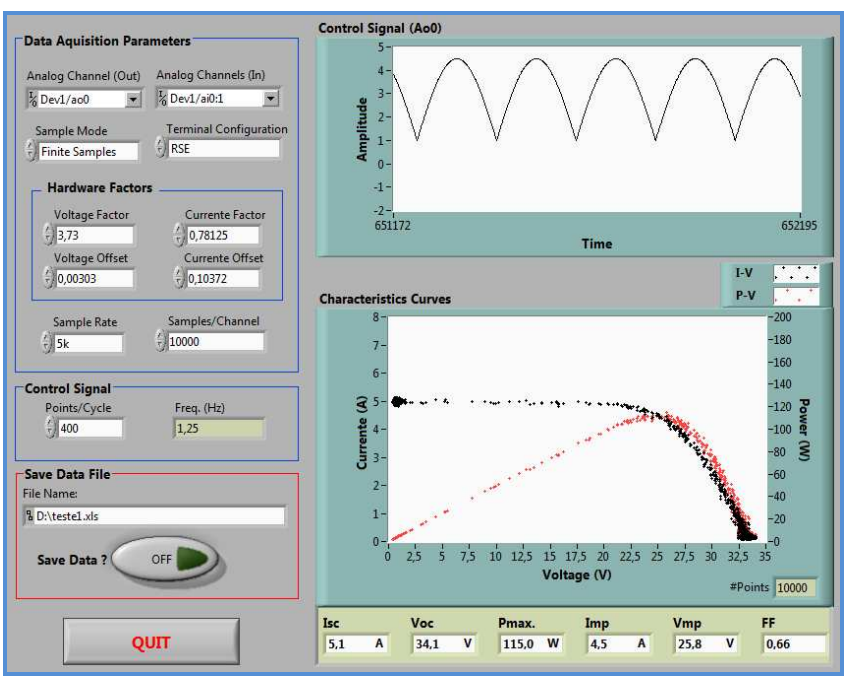

Fig. 6. User Interface for tracing the I-V and P-V characteristics of PV modules.

shown in Fig. 5(a). The same principle of [5] was used here to generate the control signal. Thus, the circuit of Fig. 5(b) is also no longer needed. The control signal is generated by using an analogue output of the USB data acquisition board with a frequency of about $2 \mathrm{~Hz}$, with 200 points per cycle. However, these parameters can be programmed by the user. Next, the electronic circuits shown in Fig. 5(d) and 4(a) are used, as described previously, to obtain the same control signal, but with galvanic isolation, to drive the MOSFET of Fig. 1.

The acquisition of the isolated signals of voltage and current is carried out via two input channels of the data acquisition board with a sample rate of $5 \mathrm{kS} / \mathrm{s}$. The control signal is generated when the application is run and, simultaneously, the acquisition of the signals of voltage and current is initiated. Then, the graphical representation of the I-V and P$\mathrm{V}$ curves is made and the main parameters of the PV module are calculated. This procedure is continuously done.

\section{Experimental Results}

In order to evaluate the performance of the proposed electronic instrument, the experimental results presented below were obtained with two different PV modules, which have the following parameters at Standard Test Conditions (STC: cell temperature of $25^{\circ} \mathrm{C}$ and irradiance of $1000 \mathrm{~W} / \mathrm{m}^{2}$ with air mass of 1.5):

- Module 1:FTS-220P with 60 cells in series, $220 \mathrm{~W}$, $V_{O C}=36.76 \mathrm{~V}, I_{S C}=8.30 \mathrm{~A}, V_{M P P}=29.38 \mathrm{~V}$, $I_{M P P}=7.51 \mathrm{~A}$;

- Module 2:EC-115, with 72 cells (two strings in parallel, of 36 cells each one), $115 \mathrm{~W}, V_{O C}=21.3 \mathrm{~V}$, $I_{S C}=7.62 \mathrm{~A}, V_{M P P}=17.1 \mathrm{~V}$ and $I_{M P P}=6.73 \mathrm{~A}$. 
The output voltage $\left(V_{P V}\right)$ is sensed using the voltage divider $\mathrm{R}_{\mathrm{P}}$ and $\mathrm{R}_{\mathrm{Vpv}}$, shown in Fig. 1 , and the output current $\left(I_{P V}\right)$ is measured using the sensing resistor $R_{I p v}$. The voltages across $\mathrm{R}_{\mathrm{Vpv}}$ and $\mathrm{R}_{\mathrm{Ipv}}$ are amplified by means of the differential amplifiers with galvanic isolation, shown in Fig. 8. The scale factors are the following: $0.78125 \mathrm{~A} / \mathrm{V}$ for $I_{P V}$ and $3.73 \mathrm{~V} / \mathrm{V}$ for $V_{P V}$.

The tracing of the I-V and P-V characteristics of the PV module 1 (FTS-220P) are given by the LabVIEW interface as shown in Fig. 7, where the control voltage $V_{G S}$ is also shown. The interface also gives the main parameters of the PV module 1: $I_{S C}, V_{O C}, P_{M P P}, I_{M P P}, V_{M P P}$ and form factor.

In order to demonstrate the performance of the developed instrument, in field conditions, figures 8 (a) to 8(d) show the $\mathrm{I}-\mathrm{V}$ and $\mathrm{P}-\mathrm{V}$ characteristics of PV module 1 , when the cells $10,10+11,10+11+30$ and $10+11+30+31+50$ are shadowed, respectively. The characteristics without shadow have been shown in Fig. 7. When cell 10 is shadowed, the string formed by cells 1 to 20 is bypassed since the first bypass diode turns on immediately (Fig. 8(a)). Consequently, even the module output current is the same there is a drop voltage of $10 \mathrm{~V}$ in $V_{M P P}$, as shown in Fig. 8(a), which corresponds to a voltage drop of $0.5 \mathrm{~V}$ in each cell. As expected, the maximum power of the module decreased from $115 \mathrm{~W}$ to $71.3 \mathrm{~W}$. The results of Fig. 8(a) and 8(b) are similar since cells $10+11$ belong to the same string of cells. However, when also cell 30 is

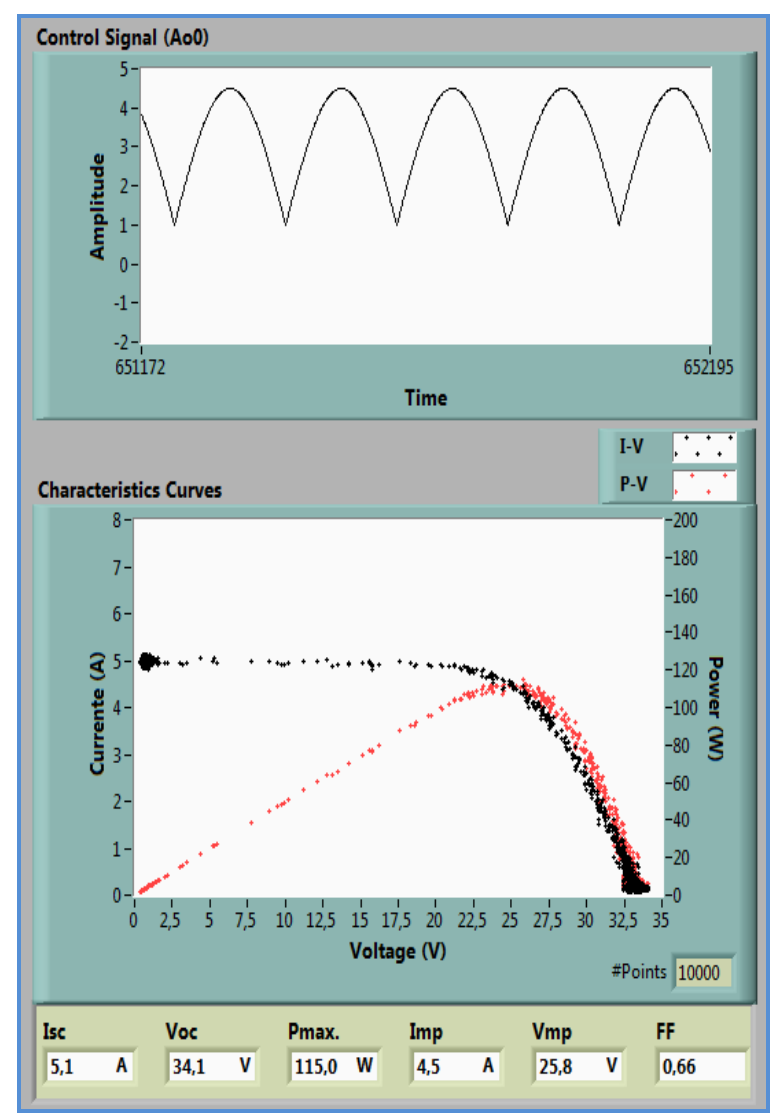

Fig. 7. Interface with the I-V and P-V characteristics of PV module 1 (FTS-220P) (below), the control voltage $V_{G S}$, and the main parameters of the module (at the bottom).

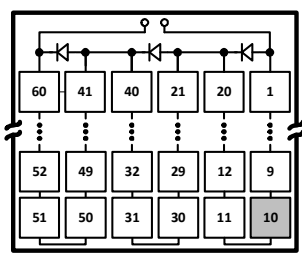

(a)

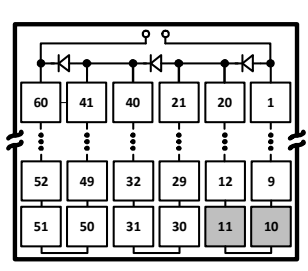

(b)
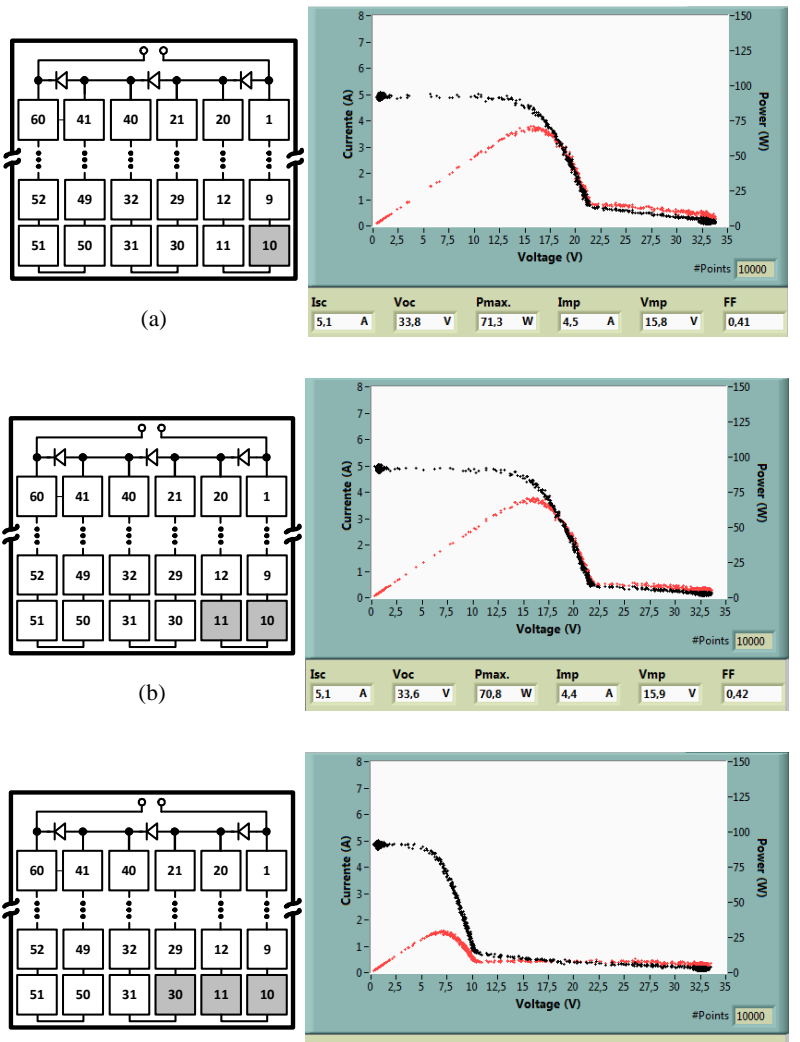

(c)
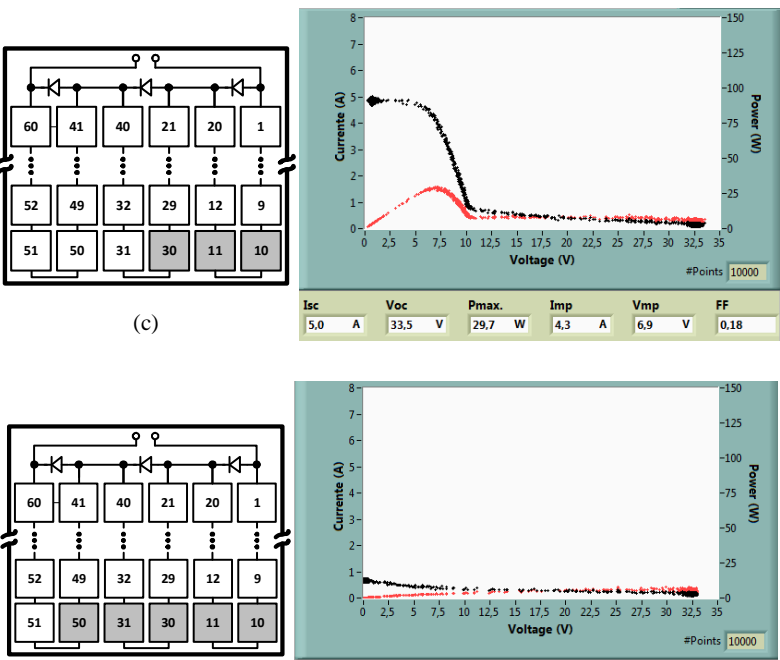

(d)

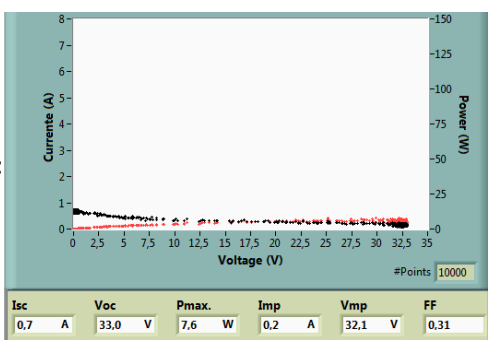

Fig. 8. I-V and P-V characteristics of PV module 1 (FTS-220P) under the effect of shadow: (a) PV module layout; (b) Cell 10 shadowed; (c) Cells 10+11 shadowed; (d) Cells 10+11+30 shadowed; Cells $10+11+30+31+50$ shadowed

shadowed, the string formed by cells 21 to 40 is bypassed by the second bypass diode, and the current flows directly through cells 41 to 60 . Of course, in this case the power is strongly reduced as can be seen in Fig. 8(c). When cell 50 is also shadowed the third bypass diode turns on and the module fails to produce energy.

Similar analyses can be made with the results obtained with the PV module 2 (EC-115), which are presented in Fig. 9. Nevertheless, the I-V and P-V characteristics, under the effect of shadow, are quite different because this module has two strings in parallel, of 36 cells each one.

\section{Conclusions}

This paper has presented a robust electronic circuit for tracing $\mathrm{I}-\mathrm{V}$ and $\mathrm{P}-\mathrm{V}$ characteristics of photovoltaic modules or low 


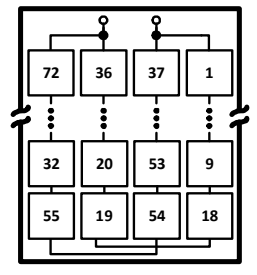

(a)
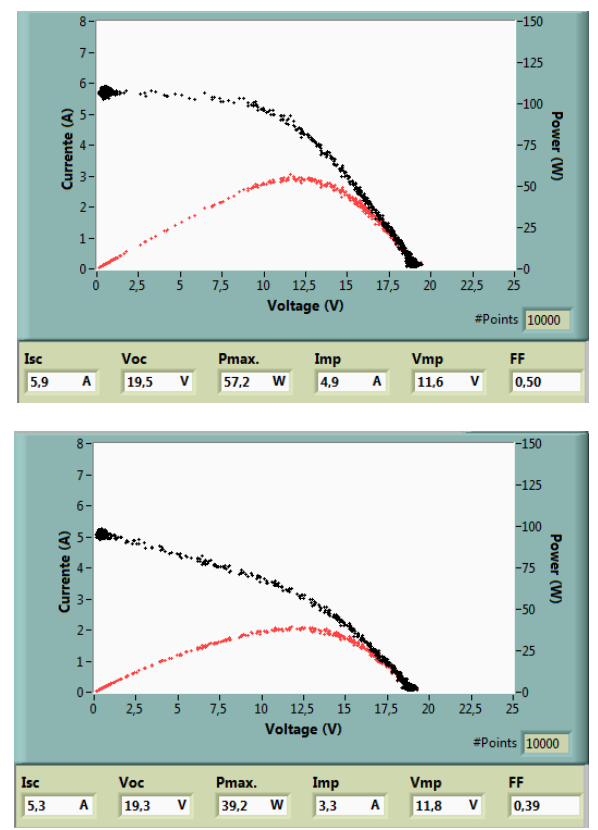

(b)

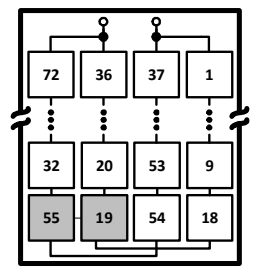

(c)

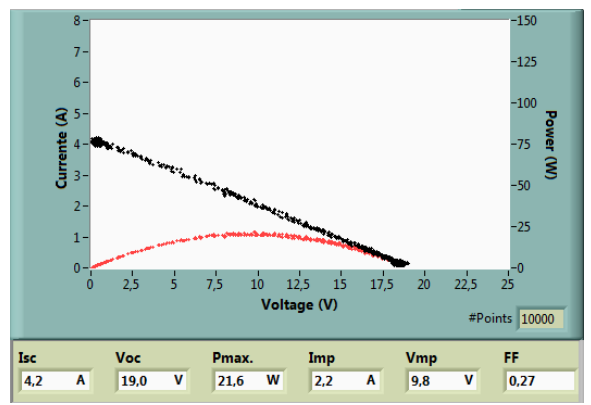

Fig. 9. I-V and P-V characteristics of PV module 2 (EC-115) under the effect of shadow: (a) Without shadow; (b) One cell shadowed; (c) Two cells shadowed, one in each string of cells.

voltage strings by tracing their I-V and P-V characteristics on an oscilloscope. All electronic circuits are based on simple, low-cost and widely used components.

The characteristics of PV modules are traced using a power MOSFET as an electronic fast varying load controlled by means of an optimized sweeping gate-source voltage, which consists of a rectified sinusoid with variable DC level for different threshold voltages. The electronic instrument includes galvanic isolation, to avoid damage of the data acquisition system, and to improve the safety of the operator, mainly in case string tests.

As an alternative to the oscilloscope, a LabVIEW application has been developed in order to offer additional processing features and flexibility. For this purpose a low-cost USB DAQ board was used. Extensive experimental tests with diferent PV modules have been carried out in real field conditions in order to demonstrate the usefulness and robustness of the proposed electronic instrument and of the LabVIEW application developed in this work.

The proposed instrument is suitable to be used in analysing the influence of field conditions, like temperature, irradiance and partial shadowing, on PV modules and low voltage PV strings performance, as well as in identifying degradation and malfunction conditions.

\section{Future Developments}

The authors are working on a new functionality of this project which aims to use the developed instrument in the tracing of $\mathrm{I}-\mathrm{V}$ characteristics of PV strings, in field conditions, which have voltages up to several hundreds of volts.

\section{References}

[1] IEA-PVPS, "Trends in Photovoltaic Applications - Survey report of selected IEA countries between 1992 and 2009”, Report IEA-PVPS T1-19:2010, [Online] Available: http:// www.iea-pvps.org/index.php?id=92.

[2] EPIA and Greenpeace, "Solar Generation 6-Solar photovoltaic electricity empowering the world: 2011", [Online] Available: http://www.epia.org/publications/epiapublications/ solar-generation-6.html.

[3] E.L. Meyer and E.E. Van Dyk, "Assessing the Reliability and Degradation of Photovoltaic Module Performance Parameters", IEEE Transactions on Reliability, Vol. 53, N. ${ }^{\circ}$, pp. 83-92, March 2004.

[4] E.E. Van Dyk, A.R. Gxasheka, E.L. Meyer, "Monitoring Current-Voltage Characteristics and Energy Output of Silicon Photovoltaic Modules", ELSEVIER, Renewable Energy 30, pp. 399-411, 2005.

[5] V. Leite, F. Chenlo, "An Improved Electronic Circuit for Tracing the I-V Characteristics of Photovoltaic Modules and Strings", in Proc. of the International Conference on Renewable Energies and Power Quality (ICREPQ'10), March 23-25, 2010.

[6] Ausias Garrigós and José Blanes, "Power MOSFET is Core of Regulated-DC Electronic Load", EDN, pp. 92-93, March 17, 2005.

[7] Yingying Kuai, S. Yuvarajan, "An Electronic Load for Testing Photovoltaic Panels", ELSEVIER, Journal of Power Sources 154, pp. 308-313, 2006.

[8] F. Recart, H. Mäckel, A. Cuevas and R.A. Sinton, "Simple Data Acquisition of the Current-Voltage and Illumination Voltage Curves of Solar Cells", in Proc. of $4^{\text {th }}$ World Conference on Photovoltaic Energy Conversion, May 2006, Vol. 1, pp. 1215-1218.

[9] Francesco De Lia, Salvatore Castello and Luigi Abenante, "Efficiency Degradation of C-Silicon Photovoltaic Modules After 22-Year Continuous Field Exposure", in Proc. of $3^{\text {rd }}$ World Conference on Photovoltaic Energy Conversion, May 2003, pp. 2105-2108.

[10] Julen J. M. Ibirriaga, Xabier M. de Mendiluce Pena, Adrian O. Dezso Sera, Remus Teodorescu, "Low-cost, high flexibility IV curve tracer for photovoltaic modules", in Proc. of $12^{\text {th }}$ International Conference on Optimization of Electrical and Electronic Equipment, OPTIM 2010, May 20 - 22, 2010, pp 1210-1215.

[11] E.E. Van Dyk, A.R. Gxasheka, E.L.Meyer, "Monitoring Current-Voltage Characteristics of Photovoltaic Modules", in Proc. of $29^{\text {th }}$ IEEE Photovoltaic Specialists Conference, 2002, pp. 1516-1519.

[12] Muhammad H. Rashid, Power Electronics Handbook, Academic Press, 2001.

[13] Stuart R. Wenham, Martin A. Green, Muriel E. Watt and Richard Corkish, Applied Photovoltaics, $2^{\text {nd }}$ edition, Earthscan Publications, 2007. 